DOI: $10.22456 / 2316-2171.106651$

\title{
RESENHA: COVID-19 E O CUIDADO \\ DE IDOSOS: RECOMENDAÇÕES PARA INSTITUIÇÕES DE LONGA PERMANÊNCIA
}

\author{
Bartolomeu Fagundes de Lima Filho ${ }^{1}$ \\ Nathalia Priscilla Oliveira Silva Bessa² \\ Fabricia Azevêdo da Costa Cavalcanti ${ }^{3}$
}

NUNES, Vilani Medeiros de Araújo Nunes et al.

COVID-19 e o cuidado de idosos: recomendações para instituições de longa permanência. 1. ed.

Natal: EDUFRN. 2020. ISBN: 978.65-5569-038-5.

1 Fisioterapeuta. Mestre em Fisioterapia pela Universidade Federal do Rio Grande do Norte (UFRN). Discente de doutorado em Fisioterapia pela Universidade Federal do Rio Grande do Norte (UFRN), departamento de Fisioterapia. E-mail: bartolomeu_fagundes2@hotmail.com

2 Fisioterapeuta. Mestre em Fisioterapia pela Universidade Federal do Rio Grande do Norte (UFRN). Discente de doutorado em Fisioterapia pela Universidade Federal do Rio Grande do Norte (UFRN), departamento de Fisioterapia. E-mail: nathyzinhasilva@gmail.com

3 Fisioterapeuta. Doutora em Ciências da Saúde pela Universidade Federal do Rio Grande do Norte (UFRN). Docente do curso de Fisioterapia da Universidade Federal do Rio Grande do Norte (UFRN), departamento de Fisioterapia. E-mail: fabriciacosta@ufrnet.br 
A cartilha "COVID-19 e o cuidado de idosos: recomendações para Instituições de Longa Permanência" lançado pela Editora da UFRN é composta por orientações simples sobre as formas de enfrentamento ao COVID-19. Esta foi organizada pela Prof ${ }^{a}$. Dra. Vilani Medeiros de Araújo Nunes, professora e pesquisadora do Departamento de Saúde Coletiva da UFRN. Além da autora mencionada, a cartilha possui mais autores: Flávia Machado (doutora em saúde coletiva), Miria Morais (especialista em enfermagem do trabalho), Larissa Costa (especialista em nutrição clínica funcional e saúde pública), Izabel Nascimento (especialista em gerontologia), Thaiza Xavier (doutora em ciências da saúde) e Maria da Silva (técnica em administração).

A interdisciplinaridade permeou a leitura da cartilha por todas as partes. O fato de o mesmo ter sido escrito por profissionais de saúde de áreas distintas permite uma abordagem que mescla diversas áreas e proporciona uma maior abrangência da obra. Ademais, as responsáveis pela obra se destacam pela participação ativa na busca da qualidade de vida para o idoso do Rio Grande do Norte, fazendo o diferencial para essa parcela populacional. A obra possui um embasamento teórico bem fundamentado e o seu conteúdo pode ser utilizado por gestores, profissionais e interessados no tema. Na apresentação da cartilha há uma informação importante, adiante:

\begin{abstract}
As recomendações seguem as orientações divulgadas pela Organização Mundial da Saúde (OMS), pelo Ministério da Saúde, por meio da Agência Nacional de Vigilância Sanitária (ANVISA), e pela literatura científica. Todavia, essas orientações poderão vir a ser complementadas com novas informações, documentos e notas técnicas atualizadas pelo Ministério da Saúde em nosso país, considerando que se trata de uma situação de pandemia com um microrganismo novo no mundo e, portanto, com poucas evidências sobre ele (NUNES et al., 2020, p. 5).
\end{abstract}

Fazendo uma reflexão sobre o delineamento da obra, nota-se claramente que ela possui uma sequência lógica sobre o tema abordado. Seu conteúdo versa sobre o surgimento da COVID-19 com suas informações gerais e vai adentrando no ambiente específico de uma Instituição de Longa Permanência para Idoso (ILPI) para só então emanar o conteúdo proposto. Apesar de bem ilustrada, a obra não apresenta uma forma didática para que um indivíduo idoso residente de uma ILPI e analfabeto tenha esse conhecimento. Como ela se destina também a pessoas interessadas no tema, o perfil de idoso mencionado é comum nas ILPI do Nordeste brasileiro.

A obra pode ser utilizada como instrumento facilitador de conhecimento sobre o tema neste cenário, inclusive, como forma de educação continuada e 
permanente para a equipe que trabalha no local. Neste contexto, o estudo de Carvalho (2014) mostrou que 78\% das ILPI do Nordeste não possuem política de educação permanente em Gerontologia. Esse déficit educacional mostra uma série de lacunas com relação à formação profissional de pessoas que lidam diretamente com o idoso. Esse déficit pode ser justificado pela falta de uma política de gestão preocupada com o atendimento prestado. $\mathrm{O}$ material em questão é um recurso para promoção da educação nesses ambientes. A cartilha é dividida em 10 seções ilustradas e possui uma diagramação colorida e com representação de imagens de idosos em diversas situações que envolvem a COVID-19 (Figura 1). Suas seções englobam questões específicas sobre a doença, seu surgimento, etc., evoluindo para a área multidisciplinar, abrangendo saúde mental, saúde coletiva, aspectos epidemiológicos, dentre outros.

Figura 1 - Capa da cartilha. Natal/RN, 2021.

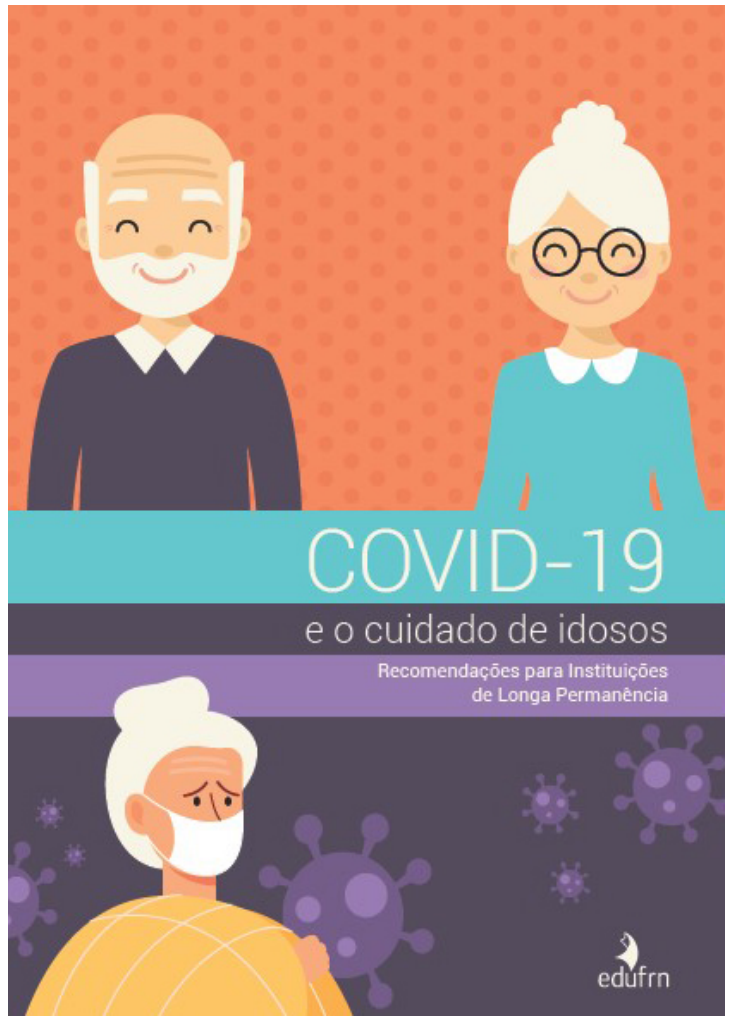

Fonte: NUNES et al., 2020. 
A primeira seção leva como título "COVID-19: informações gerais". Nesta, as autoras mencionam sobre o que é a doença e como ela surgiu, bem como o tempo de vida do coronavírus nas diferentes superfícies e suas formas de contaminação. Os sinais e sintomas também foram expostos de forma didática e fácil de entender. A conclusão desta seção versa sobre os grupos de risco para introduzir a próxima seção. Partindo de um ponto de vista reflexivo, esta seção inicial é fundamental para introduzir o tema e mostrar que o idoso merece uma atenção especial frente a essa situação de pandemia.

A segunda seção leva como título "Pessoas idosas: ciclo de vida com maior vulnerabilidade à COVID-19". Este tópico é importante por enfatizar e justificar que os idosos formam um grupo de risco para os acometimentos mais negativos da COVID-19, pincipalmente se possuírem alguma condição crônica envolvida. Ainda, trazem uma ligação da imunossenescência ${ }^{4}$ com o aumento de doenças infectocontagiosas. Apesar desta seção possui um teor mais fisiopatológico, a linguagem é acessível e clara para os usuários, focando no entendimento de que pessoas acima de 60 anos precisam se cuidar com mais atenção e afinco. Existe, também, um gráfico demonstrativo da quantidade de pessoas mortas em Wuhan, na China, mostrando o aumento exponencial na faixa etária dos idosos. A finalização desta seção retrata que o idoso precisa adotar as mesmas medidas de prevenção das demais faixas etárias e que precisa dar continuidade aos tratamentos habituais que ele faz. Este aspecto é de importante reflexão, visto que muitos idosos tendem a evitar consultas médicas e tratamentos que necessitem sair de suas casas, porém, o descontrole das comorbidades também envolve um risco adicional.

A terceira seção é intitulada “O contexto das Instituições de Longa Permanência para Idosos (ILPI)". O início desta seção conta com a justificativa do fato de que os idosos que vivem em uma ILPI possuem alto risco para infecção, principalmente pelo acometimento de doenças crônicas, idade avançada, dificuldade para realizar atividades de vida diária, convivência em aglomerados e contato com pessoas externas. As autoras ainda associam os idosos institucionalizados à pouca ingestão de água, fato que possibilita a desidratação. Esta seção traz a seguinte reflexão: o ambiente é propício ao contágio, portanto, é necessário um cuidado especial para diminuir os riscos nesse cenário. Ainda, outro ponto que chama a atenção é que os idosos residentes geralmente possuem contato um com o outro e isso possibilita o contágio em massa dos idosos que convivem nesse ambiente.

4 Refere-se às disfunções que ocorrem no sistema imunológico que se relacionam com o processo de envelhecimento que facilitam o surgimento de doenças infecciosas ou crônico-degenerativas (TONET; NÓBREGA, 2008). 
A quarta seção recebe o título de "Principais cuidados que devem ser adotados nas ILPI". Nesta seção, a leitura permeia os cuidados em um ambiente desafiador de ILPI. As normas de funcionamento precisam ser seguidas minuciosamente para diminuição do risco de contágio. Essas medidas são: restrição de entrada e circulação de pessoas (talvez seja a norma com mais repercussão da saúde mental dos idosos), adoção de protocolos de higienização de superfícies, higienização das mãos, cuidados para os profissionais, atenção na segurança alimentar, cuidados com saúde mental de profissionais e residentes e vigilância dos casos suspeitos. A seção segue de várias orientações detalhadas de cuidados específicos, como a higiene das mãos com álcool em gel, uso de equipamentos de proteção individual, visitas, práticas sanitárias, restrição de saída de idosos, isolamento, plano de contingência, utilização de máscara e cuidados com vacinação. Esta seção aborda uma temática importante, visto que restringir as visitas aos idosos residentes é algo complexo. Este eixo reflete diretamente na sensação de solidão reportada pelos idosos institucionalizados. Estudo realizado em 14 ILPI da cidade de Bragança (Portugal) com 186 idosos mostrou que $46 \%$ da amostra apresentou diagnóstico de depressão e esse índice se relacionou diretamente com a solidão (VAZ; GASPAR, 2011). A conscientização dos idosos acerca do isolamento social é fundamental para que eles entendam a necessidade de viver dessa forma.

A quinta seção intitulada "Medidas a ser instituídas mediante pessoas idosas com sintomas indicativos de comprometimento respiratório" aborda os cuidados específicos que devem ser tomados na ocorrência de um idoso com suspeita ou confirmação de infecção pela COVID-19. Tais medidas são de grande importância para evitar a disseminação do vírus dentre os residentes das ILPI. A seção ressalta inicialmente a importância da limpeza e desinfecção das superfícies mais tocadas e banheiros, evidenciando que sejam feitas no mínimo duas vezes ao dia. Em seguida, discorre sobre cuidados ao tossir, espirrar, higiene das mãos, uso de cartazes com instruções e finaliza abordando a importância de uma avaliação da gravidade do idoso que apresente alguma sintomatologia através de um checklist contido nesta seção, que avalia sinais e sintomas da síndrome gripal. Ao final, reforça-se a importância da notificação dos casos às autoridades de saúde.

A sexta seção relata as "Medidas a ser instituídas mediante funcionários com sintomas respiratórios". Esta seção reforça as informações sobre a importância das máscaras pelos profissionais que trabalham na ILPI, bem como o uso correto, seguindo as recomendações de colocação e descarte da mesma. A seção segue com várias orientações sobre cuidados específicos com o funcionário apresentando alguma sintomatologia gripal: afastamento das atividades, 
encaminhamento médico e comunicação dos casos às autoridades sanitárias. Esta seção reflete os cuidados que o próprio profissional deve ter para poder lidar com esse grupo populacional. É importante salientar o cuidado redobrado com profissionais que trabalham na linha de frente de combate à COVID-19 e mesmo assim mantém suas atividades em ILPI, visto o risco aumentado de transmissibilidade.

A sétima seção leva como título "Alimentos, COVID-19 e boas práticas em ILPI". Inicialmente, é enfatizada a importância de se oferecer alimentos seguros e de qualidade aos idosos, favorecendo a manutenção de uma vida saudável e reduzindo o risco de transmissão do vírus. Em seguida, são realizadas recomendações relacionadas ao recebimento de alimentos a fim de se reduzir a possibilidade de contaminação dos profissionais que atuam nas ILPI e idosos residentes. As recomendações vão desde o recebimento dos alimentos, higienização de embalagens, frutas, verduras e alimentos consumidos crus, até a reiteração das medidas de higiene já abordadas no material.

Na oitava seção intitulada "Saúde mental em tempos de coronavírus", é abordada a importância do bem-estar psicológico e contentamento no processo na velhice. É enfatizada a questão do envelhecimento com qualidade vida, apresentando pontos que podem contribuir para o aumento ou diminuição desta. O conceito de qualidade de vida é aprofundado e os aspectos envolvidos são esclarecidos, bem como as estratégias para manter a interação com a família e aplicar o isolamento social, com o auxílio dos cuidadores dos idosos e seguindo todas as recomendações de higiene. A seção destaca que, durante o período de isolamento social, os idosos poderão apresentar possíveis alterações de humor e comportamento e quais devem ser as medidas frente a essas mudanças. Por fim, é citado que os profissionais que atuam nas ILPI devem ser orientados para reduzir o possível estresse, o desgaste físico e emocional dos idosos e cuidadores, relacionados ao isolamento social.

Apontando uma reflexão sobre esse tema, é importante salientar que a presença de depressão e sintomas depressivos é comum dentro de um ambiente de ILPI, independente de qualquer situação pandêmica. Por exemplo, em um estudo realizado em Santa Maria (RS), dos 48 idosos residentes, 43,75\% apresentavam sinais de depressão moderada e 31,25\% apresentaram sinais de depressão severa (ROSSETTO et al., 2012). Ou seja, 75\% da amostra apresentavam depressão. Essa alta prevalência é relacionada diretamente com este tópico, sendo assim, os profissionais (que serão o único contato externo dos residentes) devem trabalhar estratégias de diminuição dos sintomas depressivos destes.

A nona seção elenca as "Vacinas recomendadas para pessoas idosas" e destaca a importância da vacinação na população idosa, e quais são as vacinas 
recomendadas no calendário de vacinação do idoso determinadas pela Sociedade Brasileira de Imunizações em conjunto com a Sociedade Brasileira de Geriatria e Gerontologia. Logo após, as vacinas contra a gripe, a pneumonia, difteria, tétano e hepatite B são detalhadas com informações sobre composição, benefícios, quando e como devem ser aplicadas, quem deve tomar, finalizando com a possibilidade de reações causadas por elas.

A décima e última seção recebe o título "Algumas palavras para aprender" e é uma espécie de glossário que explica alguns dos termos abordados ao longo da cartilha e permite ao leitor a compreensão de cada um deles. São esclarecidos os seguintes termos: Sistema Único de Saúde (SUS), Ministério da Saúde, Epidemia, Pulmões, Organização Mundial de Saúde (OMS), Propagação, Diagnóstico, Sintomas, Doenças autoimunes e Micro-organismos.

\section{Considerações finais}

A cartilha "COVID-19 e o cuidado de idosos: recomendações para Instituições de Longa Permanência" lançada pela Editora da UFRN (EDUFRN) possui uma temática relevante, abrangente, atual e importante. O material condiz com documentos oficiais da Organização Mundial de Saúde e pode ser eficaz no combate a COVID-19 em ILPI, cenário de muita dificuldade de controle pandêmico.

Cuidar dos grupos de risco diante de uma situação de pandemia é essencial para diminuição da disseminação do vírus e permite evitar que uma contaminação em grupo aconteça. Nem sempre a parcela populacional das ILPI é enfatizada pela mídia, pelos programas sociais e pelas políticas públicas. Isto posto, a clareza na forma de apresentação desta obra permite que o conhecimento seja disseminado por todos os leitores. A linguagem acessível e as ilustrações tornam a leitura prazerosa e essencial para quem lida com este público. Outro aspecto fundamental que a cartilha abordou é a importância da educação em saúde para os familiares dos idosos residentes, afinal, se eles não se cuidam, a consequência pode ser generalizada.

Por fim, a disseminação do conteúdo deste material fomenta uma rede de cuidados ímpar com a população idosa. Esta resenha crítica facilita a divulgação e o conhecimento acerca do tema. 


\section{referências}

CARVALHO, Vanessa Lôbo de. Perfil das instituições de longa permanência para idosos situadas em uma capital do Nordeste. Cadernos Saúde Coletiva, Rio de Janeiro, v. 22, n. 2, p. 184-191, jun. 2014

NUNES, Vilani Medeiros de Araújo Nunes et al. COVID-19 e o cuidado de idosos: recomendações para instituições de longa permanência. 1. ed. Natal: EDUFRN. 2020.

ROSSETTO, Maíra et al. Depressão em idosos de uma instituição de longa permanência. Revista de Enfermagem da UFSM, Porto Alegre, v. 2, n. 2, p. 347-352, abr. 2012.

TONET, Audrey Cecília; NÓBREGA, Otávio de Tolêdo. Imunossenescência: a relação entre leucócitos, citocinas e doenças crônicas. Revista Brasileira de Geriatria e Gerontologia, v. 11, n. 2, p. 259-273, ago. 2008.

VAZ, Sérgio Filipe Alves; GASPAR, Nuno Miguel Soares. Depressão em idosos institucionalizados no distrito de Bragança. Revista de Enfermagem Referência, Coimbra, n. 4, p. 49-58, jul. 2011.

Data de Submissão: 19/08/2020

Data de Aprovação: 19/01/2021 